\title{
Thyroid Incidentaloma
}

\author{
Seema Singh • Anutosh Singh • A. K. Khanna
}

Received: 25 August 2011 / Accepted: 24 October 2011 / Published online: 23 November 2011

(C) Indian Association of Surgical Oncology 2011

\begin{abstract}
Because of emerging investigation modalities many of the thyroid lesions are picked up and that poses a big dilemma about management of such lesions. Majority of these lesions especially in iodine-deficient regions, are not significant and may be only followed up without any active treatment but, sometimes the small lesions may be microcarcinoma. This article discusses about the reliability of clinical examination of neck for detection of such lesions, the controversy of such lesion being benign or malignant, and how to evaluate these lesions and the recommendation as per American Thyroid Association guidelines.
\end{abstract}

Keywords Thyroid Carcinoma - Benign · Microcarcinoma · Guidelines $\cdot$ Incidentaloma

\section{Introduction}

The lesions, which are referred to as "incidentaloma" are small and clinically nonpalpable and are incidentally discovered on ultrasonography. During the past decade, with the use of improved technology, the discovery of subclinical nodules in thyroid, pituitary and adrenal gland has increased[1,2]. The thyroid incidentalomas are nodules, usually less than $10 \mathrm{~mm}$ in diameter and not more than $15 \mathrm{~mm}$. The discovey of one or more nodules within an otherwise clinically normal thyroid gland increases concern about malignancy and creates a difficulty in treatment decision making both for clinician and for the patient also. A nodule $15 \mathrm{~mm}$ or more in

S. Singh $\cdot$ A. Singh $\cdot$ A. K. Khanna $(\bowtie)$

Department of General Surgery, Institute of Medical Sciences,

Banaras Hindu University,

Varanasi 221005, India

e-mail: akhannabhu@gmail.com the posteromedial aspect of the gland may be impalpable whereas one of less than $10 \mathrm{~mm}$ in the isthmus might be appreciable clinically. Such categorization is useful in decision making regarding management[3].

\section{Incidentaloma and Microcarcinoma}

The term incidentaloma is used when an undiagnosed nodule is discovered and, if a malignancy is subsequently identified then the term microcarcinoma is used. Microcarcinomas are occult carcinomas and are small, $<0.5 \mathrm{~cm}$ in diameter, papillary in type and shows benign behavior [4].

\section{Epidemiology}

The prevalence of palpable thyroid nodule in iodine-replete population is about $5 \%$ and incidence of about 1 per 1,000/ year[5], whereas ultrasonographically detected thyroid nodules are more common (17-67\%). But still, thyroid cancer is uncommon (20-80 per million/year) and death rate from thyroid cancer is $5-8$ per million/year. Now it is clear that malignancy in the multinodular goiter thyroid has the same prevalence as in the solitary thyroid nodule[6]. In North America, the incidence of thyroid nodule detected by palpation is estimated to be $0.1 \%$ per year, with a prevalence between $4 \%$ and $7 \%$ in general population [7]. The prevalence of occult thyroid cancer in the United States ranges from $0.45 \%$ to $13 \%$ [8]. Similar prevalence have been seen in population outside the united states [9].

\section{Risk Factors}

Thyroid nodules are more common in women and increases with advancing age. These are also prevalent in areas with 
iodine deficiency and this risk further increases following exposure to external radiation [7]. Various studies have been conducted so far and has been proposed that most patients with an occult cancer were in the fourth to seventh decade of life: where as no significant difference was seen in prevalence between the two sexes [10]. Sampson and colleagues compared the prevalence of thyroid cancer in Minnisota with that in Japan and found that the differences in age, sex, and exposure to radiation did not influence their prevalence. In another study by Hanson et al., it was proposed that the exposure of upper body to radiation increases the risk for malignancy in thyroid gland [11]. Other studies have shown the overall incidence of malignancy in irradiated glands to be as high as $32 \%$ to $57 \%$ [12]. $5 \%-10 \%$ of thyroid nodules undergo malignant tansformation depending on age, gender, history of radiation exposure and a family history of cancer [13]. A positive dose of low dose radiotherapy (i.e., $6.5-4,000 \mathrm{cGY}$ ) causes a $40 \%$ risk of thyroid cancer [14]. These results suggest that geographic differences including genetic, social, and cultural factors should be considered when patients are examined for occult cancer, especially because no differences were noted in the prevalence of occult cancer between Japanese persons living in Hiroshima and those living in Haawaii [8].

\section{Clinical Examination-Is it Reliable?}

Because the thyroid gland is superficially located, it is easily palpated. It is still debatable that whether thyroid palpation is best done from the front or from the back of the patient [15].Nodules that are $1 \mathrm{~cm}$ or larger in diameter are palpated when they are fovourably situated . A complete examination should consist of size, shape, and consistency of nodule. A nodule that is located deep within the gland or on the posterior surface is difficult to palpate than that of one located on the anterior surface [12]. It is even more difficult to palpate nodule in patients with short and fat neck. The accuracy of thyroid palpation depends on the experience of the examiner also. Moreover, even with experience and careful technique, phycisians may fail to detect many nodules smaller than $1 \mathrm{~cm}$ in diameter [16]. In a study by Brander and colleagues [1], one half of nodules discovered on ultrasonography had escaped detection on clinical examination; approximately one third of the nodules that had not been detected by palpation were larger than $2 \mathrm{~cm}$ in diameter. However, a prominent but normal thyroid gland in a patient with a thin neck may be perceived as an abnormality of the thyroid gland [15]. So, clinical palpation is thus not a precise tool for assessing abnormality of thyroid gland, and its reliability is influenced by the size and location of the nodule, the size and shape of the neck and the experience of the examiner. In their study, Christensen (1985) proposed that the sensitivity of palpation of the thyroid gland in terms of size and nodularity was $38 \%$ [17].

\section{Thyroid Incidentaloma—Benign or Malignant?}

Certain clinical features are regarded as highly suspicious of thyroid carcinoma in a patient with an incidentally discovered thyroid nodule or thyroid incidentaloma. These include (1) a nodule discovered in childhood or adolescence [18], (2) nodule being discovered in a male patient [19], or (3) a nodule found in those with a history of exposure to radiation or (4) a nodule in a patient having a family history of medullary carcinoma of thyroid. The patients from an iodine-deficient areas are also at higher risk of thyroid malignancy [20]. Hamming et al. rated various clinical factors as having high, moderate, or low clinical suspicion for thyroid cancer, and showed that patients with one clinical factor with high suspicion for thyroid cancer had a $71 \%$ incidence of cancer in the nodule, where as those with a low suspicion led to a $100 \%$ chance of cancer [21]. It is an interesting fact that although family history of medullary carcinoma of thyroid, rapid tumor growth, very firm nodule, and even vocal cord paralysis were all factors shown to be associated with a high suspicion of thyroid carcinoma, age less than 20 years, male sex, and head and neck irradiation were not shown to have predictive value [21]. Thyroid carcinoma is relatively uncommon accounting for approximately 1,000 new cases and 300 deaths in England and Wales per year. The main objective while investigating patients with an incidentally detected solitary nodule is to identify the patients with differentiated thyroid carcinoma who requires treatment, and avoding unnecessary investigations and treatment in majority. There are evidences from epidemiological studies (e.g., Framingham cohort) that suggest the likelihood of an incidentaloma to be malignant is very low. Moreover, as the occult malignancy may be discovered in upto $2 \%$ of thyroid glands that are normal on palpation, this may be of little clinical relevance [22]. However, tumor $<1 \mathrm{~cm}$ in size can still metastasize and can cause death [4].

In an autopsy study of 138 patients with no known thyroid disease, Komorowski and Hansen [23] reported malignant nodules in only $3 \%$ of the thyroid glands. In a cases series, proposed by Horlocker and associates [24], only $14(2 \%)$ incidental thyroid carcinoma were among 689 patients who had neck exploration for parathyroid 
disease. These included 6 clinically palpable nodules that had a mean diameter of $3.0 \mathrm{~cm}$ and 7 nodules had a mean diameter of $1.0 . \mathrm{cm}$ and were identified only on ultrasonography. In addition, 1 patient had an occult carcinoma that was not detected on ultrasonography. The low risk for malignancy was further confirmed by Brander and coworkers, who reported that none of 30 patients were randomly selected for fine-needle aspiration biopsy had thyroid cancer [25].

How to Evaluate Thyroid Nodules and Incidentaloma Whenever a thyroid nodule is discovered, a complete history and physical examination regarding thyroid gland and adjacent cervical lymph nodes should be obtained. Family history of thyroid carcinoma, or thyroid cancer syndrome (e.g., Cowden's syndrome, familial polyposis, Carney complex multiple endocrine neoplasia [MEN] 2, Werner syndrome) in a first degree relative, exposure to ionizing radiation in childhood or adolescence and rapid growth and hoarseness [26]. Relevant physical findings suggestive of malignancy include vocal cord paralysis, lateral cervical lymphadenopathy, and fixation of the nodule to surrounding tissues.

\section{Investigations}

Thyroid gland nodules are investigated in order as follows:

\section{A. Biochemical markers-}

1. Serum TSH with ultrasound (US) and with or without scan-If the serum TSH is subnormal, a radionuclide thyroid scan should be obtained to document whether the nodule is hyperfunctioning (i.e., tracer uptake is greater than the surrounding normal thyroid), isofunctioning or "warm" (i.e., tracer uptake is equal to the surrounding thyroid), or nonfunctioning (i.e., has uptake less than the surrounding thyroid tissue). Since hyperfunctioning nodules rarely harbor malignancy, if it is found that corresponds to the nodule in question, no further cytological evaluation is necessary. If overt or subclinical hyperthyroidism is present, additional evaluation is required. Higher serum TSH, even within the upper part of the reference range, is associated with increased risk of malignancy in a thyroid nodule [27]

2. Serum $\mathbf{T g}$-Serum thyroglobulin may be raised in variety of thyroid disorders, so it's not specific for thyroid incidentaloma and hence routine estimation is not recommended [28]

3. Serum calcitonin - The utility of serum calcitonin has been evaluated in a series of prospective, nonrandom- ized studies [29]. The data suggest that the use of routine serum calcitonin for screening may detect Ccell hyperplasia and medullary thyroid cancer at an earlier stage and overall survival may be improved. However, most studies rely on pentagastrin stimulation testing to increase specificity. A recent cost-effectiveness analysis suggested that calcitonin screening would be cost-effective in the United States [30]. If the serum calcitonin determination is obtained and the level is greater than $100 \mathrm{pg} / \mathrm{mL}$, medullary cancer is likely present [31].

B. Fine-needle aspiration cytology (FNAC) - FNA is the most accurate and cost-effective method for evaluating thyroid nodules. Retrospective studies have reported lower rates of both nondiagnostic and falsenegative cytology specimens from FNA procedures performed via ultrasound (US) guidance compared to palpation [32].Therefore, for nodules with a higher likelihood of either a nondiagnostic cytology $(>25-$ $50 \%$ cystic component) [33]or sampling error (difficult to palpate or posteriorly located nodules), US-guided FNA is preferred. If the diagnostic US confirms the presence of a predominantly solid nodule corresponding to what is palpated, the FNA may be performed via palpation or US guidance. Traditionally, FNA biopsy results are divided into four categories:(i) nondiagnostic, (ii) malignant (risk of malignancy at surgery $>95 \%$ ), (iii) indeterminate or suspicious for neoplasm, and (iv) benign. The recent National Cancer Institute Thyroid Fine-Needle Aspiration State of the Science Conference proposed a more expanded classification for FNA cytology that adds two additional categories: suspicious for malignancy (risk of malignancy 50-75\%) and follicular lesion of undetermined significance (risk of malignancy $5-10 \%$ ). The conference further recommended that "neoplasm, either follicular or Hurthle cell neoplasm" be substituted for "indeterminate" (risk of malignancy 15$25 \%$ ) [34]. Routine FNA is not recommended for subcentimeter nodules. However, the presence of a solid hypoechoic nodule with microcalcifications is highly suggestive of PTC. Although most micropapillary carcinomas may be incidental findings, a subset may be more clinically relevant, especially those $>5 \mathrm{~mm}$ in diameter [35].These include nodules that have abnormal lymph nodes detected clinically or with imaging at presentation [36]. Therefore, after imaging a subcentimeter nodule with a suspicious appearance, sonographic assessment of lateral neck and central neck lymph nodes (more limited due to the presence of the thyroid) must be performed. Detection of abnormal lymph nodes should lead to FNA of the lymph node. Other groups of patients for whom consideration of FNA of a sub- 
centimeter nodule may be considered include those with a higher likelihood of malignancy (high risk history): 1) family history of PTC [37]; 2) history of external beam radiation exposure as a child [38]; 3) exposure to ionizing radiation in childhood or adolescence [39]; 4) history of prior hemithyroidectomy with discovery of thyroid cancer; and 5) ${ }^{18}$ FDGPET-positive thyroid nodules. Mixed cystic-solid nodules and predominantly cystic with $>50 \%$ cystic component are generally evaluated by FNA with directed biopsy of the solid component (especially the vascular component.) Cyst drainage may also be performed, especially in symptomatic patients.

C. Imaging studies-various imaging modalities are utilized to detect and evaluate thyroid nodules, like US, CT,MRI or FDG-PET scan.

(i) Ultrasonogphy for FNA Decision Making Various sonographic characteristics of a thyroid nodule have been associated with a higher likelihood of malignancy [40]. These include nodule hypoechogenicity compared to the normal thyroid parenchyma, increased intranodular vascularity, irregular infiltrative margins, the presence of microcalcifications, an absent halo, and a shape taller than the width measured in the transverse dimension. With the exception of suspicious cervical lymphadenopathy, no single sonographic feature or combinations of features is adequately sensitive or specific to identify all malignant nodules. However, certain features and combination of features have high predictive value for malignancy. Furthermore, the most common sonographic appearances of papillary and follicular thyroid cancer differ. A PTC is generally solid or predominantly solid and hypoechoic, often with infiltrative irregular margins and increased nodular vascularity. Microcalcifications, if present, are highly specific for PTC, but may be difficult to distinguish from colloid. Conversely, follicular cancer is more often iso-to hyperechoic and has a thick and irregular halo, but does not have microcalcifications [41]. Follicular cancers that are $<2 \mathrm{~cm}$ in diameter have not been shown to be associated with metastatic disease [42]. Certain sonographic appearances may also be highly predictive of a benign nodule. A pure cystic nodule, although rare $(<2 \%$ of all nodules), is unlikely to be malignant [43]. In addition, a spongiform appearance (an aggregation of multiple microcystic components in more than $50 \%$ of the nodule volume) is $99.7 \%$ specific for identification of a benign thyroid nodule. In a recent study, a spongiform appearance had a negative predictive value for malignancy of 98.5\% [44]. Elastography is an emerging and promising sonographic technique that requires additional validation with prospective studies [45].
Sonographic and Clinical Features of Thyroid Nodules and Recommendations for FNA [46]

\begin{tabular}{|c|c|c|}
\hline $\begin{array}{l}\text { Nodule sonographic or clinical } \\
\text { features }\end{array}$ & \multicolumn{2}{|c|}{$\begin{array}{l}\text { Recommended nodule threshold } \\
\text { size forFNA }\end{array}$} \\
\hline High-risk history & (size) & (Recommendation) \\
\hline $\begin{array}{l}\text { Nodule with suspicious } \\
\text { sonographic features }>\end{array}$ & $5 \mathrm{~mm}$ & A \\
\hline $\begin{array}{l}\text { Nodule without suspicious } \\
\text { sonographic features }>\end{array}$ & $5 \mathrm{~mm}$ & I \\
\hline Abnormal cervical lymph nodes & All & A \\
\hline $\begin{array}{l}\text { Microcalcifications present in } \\
\text { nodule } \geq\end{array}$ & $1 \mathrm{~cm}$ & $\mathrm{~B}$ \\
\hline \multicolumn{3}{|l|}{ Solid nodule } \\
\hline and hypoechoic $>$ & $1 \mathrm{~cm}$ & $\mathrm{~B}$ \\
\hline and iso-or hyperechoic & $\geq 1-1.5 \mathrm{~cm}$ & $\mathrm{C}$ \\
\hline \multicolumn{3}{|l|}{ Mixed cystic-solid nodule } \\
\hline $\begin{array}{l}\text { with any suspicious ultrasound } \\
\text { features }\end{array}$ & $\begin{aligned} \geq & 1.5- \\
& 2.0 \mathrm{~cm}\end{aligned}$ & $\mathrm{~B}$ \\
\hline $\begin{array}{l}\text { without suspicious ultrasound } \\
\text { features }\end{array}$ & $\geq 2.0 \mathrm{~cm}$ & $\mathrm{C}$ \\
\hline Spongiform nodule & $\geq 2.0 \mathrm{~cm}$ & $\mathrm{C}$ \\
\hline Purely cystic nodule & $\begin{array}{l}\text { FNA not } \\
\text { indicated }\end{array}$ & $\mathrm{E}$ \\
\hline
\end{tabular}

(ii) ${ }^{18}$ F-FDG PET FDG PET is increasingly used in the diagnostic workup and follow-up of patients Whole-body 18 F-FDG PET is a noninvasive method and plays an important role in the evaluation for metastases in patients with various kinds of malignancies[47]. Thyroid incidentalomas with focal increased FDG uptake were found in 1.2$4.3 \%$ of patients or healthy subjects on PET examination in several studies [48, 49]. Some reports indicate that focal thyroid incidentalomas found on FDG PET have a high prevalence of thyroid malignancy [50]. Although thyroid nodules are commonly detected incidentally during CT or MRI of the head and neck, as well as of the chest, the differentiation of benign from malignant lesions is impossible using these techniques unless invasion into adjacent structures is seen [51]. Thyroid incidentalomas with focal increased FDG uptake were found in $1.2-4.3 \%$ of patients or healthy subjects on PET examinations according to several studies [48, 49]. Although several authors have reported that FDG accumulation may vary in the normal thyroid gland and that diffuse or focal moderate to intense FDG activity in the thyroid gland may be normal [52]. Recent studies have shown that focal thyroid incidentalomas with uptake on FDG PET have a high prevalence of thyroid malignancy [49].

Management of Thyroid Nodules in Special Conditions-

1. Children-Thyroid nodules occur less frequently in children than in adults. In a study conducted in United 
States where 5,000 children between 11 and 18 years were included, palpable thyroid nodules occurred in approximately 20 per 1,000 children, with an annual incidence of seven new cases per 1,000 children [53]. Other studies have shown the frequency of malignancy to be higher in children than adults, in the range of 15$20 \%$. FNA biopsy is sensitive and specific in the diagnosis of childhood thyroid nodules [54].

2. Pregnancy-It is uncertain if thyroid nodules discovered in pregnant women are more likely to be malignant than those found in nonpregnant women [55], since there are no population-based studies on this question. The evaluation is the same as for a nonpregnant patient, with the exception that a radionuclide scan is contraindicated. In addition, for patients with nodules diagnosed as differentiated thyroid carcinoma(DTC) by FNA during pregnancy, delaying surgery until after delivery does not affect outcome [56]. If the FNA cytology is consistent with papillary thyroid carcinoma (PTC), surgery is recommended. However, there is no consensus about whether surgery should be performed during pregnancy or after delivery. To minimize the risk of miscarriage, surgery during pregnancy should be done in the second trimester before 24 weeks gestation [57]. However, PTC discovered during pregnancy does not behave more aggressively than that diagnosed in a similar-aged group of nonpregnant women. A retrospective study of pregnant women with DTC found there to be no difference in either recurrence, or survival rates, between women operated on during or after their pregnancy [56].A recent study reported a higher rate of complications in pregnant women undergoing thyroid surgery compared with nonpregnant women [58]. Some experts recommend thyroid hormone suppression therapy for pregnant women with FNA suspicious for or diagnostic of PTC, if surgery is deferred until the postpartum period [59].

In 1996, the American Thyroid Association (ATA) published guidelines to evaluate thyroid nodules [60]. The initial ATA guidelines were published in 2006 and relevant literature continued to be reviewed though December 2008.

American Thyroid Association (ATA) Mangement Guidelines 2009 [46] Revised American Thyroid Association management guidelines for thyroid nodules was porposed by Cooper et al. in 2009, and are as follows (Table 1):

Outcome of Thyroid Incidentaloma

It is known that most asymptomatic thyroid nodules are benign lesions. Kuma and associates examined the long term outcome of benign thyroid nodules that were untreated. Among 134 patients with cytologically benign thyroid nodules who were followed for 9 to 11 years, most nodules remained benign [61]. Only 1 patient $(0.7 \%)$ had a nodule that had been considered benign but that increased in size during follow-up; after surgical excision, this nodule was shown to be a papillary carcinoma. This clearly shows that benign thyroid nodules remain benign for a long time. Therefore, we speculate that the long-term course and final outcome of thyroid incidentalomas and palpable benign nodules would be similar if these conditions were left untreated.

\section{Long-Term Follow-up Protocol-}

Thyroid nodules diagnosed as benign require follow-up because of a low, but not negligible, false-negative rate of up to 5\% with FNA [62], which may be even higher with nodules $>4 \mathrm{~cm}$ [63]. While benign nodules may decrease in size, they often increase in size [64]. One study of cytologically benign thyroid nodules $<2 \mathrm{~cm}$ followed by ultrasonography for about 38 months found that the rate of thyroid nodule growth did not distinguish between benign and malignant nodules [65]. Nodule growth is not in and of itself pathognomonic of malignancy, but growth is an indication for repeat biopsy. For mixed cystic - solid nodules, the indication for repeat biopsy should be based upon growth of the solid component. For nodules with benign cytologic results, recent series report a higher falsenegative rate with palpation FNA (1-3\%) than with US FNA $(0.6 \%)$ [32]. Since the accuracy of physical examination for nodule size is likely inferior to that of US [16], it is recommended that serial US be used in follow-up of thyroid nodules to detect clinically significant changes in size. There is no consensus on the definition of nodule growth, however, or the threshold that would require re-biopsy. Some groups suggest a $15 \%$ increase in nodule volume, while others recommend measuring a change in the mean nodule diameter [64].Another definition of growth is a $20 \%$ increase in nodule diameter with a minimum increase in two or more dimensions of at least $2 \mathrm{~mm}$. This approximates the $50 \%$ increase in nodule volume and to be the minimally significantly recorded change in nodule size that was found by Brauer et al. [66]. A 50\% cutoff for nodule volume reduction or growth, which is used in many studies, appears to appropriate and safe, since the false-negative rate for malignant thyroid nodules on repeat FNA is low [67].

\section{Conclusion-}

In most patients with nonpalpable thyroid lesions, the risk for clinically malignant disease is low. Moreover, occult 
Table 1 American Thyroid Association guidelines for thyroid incidentaloma

American Thyroid Association (ATA) management guidelines 2009

Recommendation Grading

Serum TSH needs to be measured, if subnormal, a radionuclide scan should be done ${ }^{99 \mathrm{~m}}$ Tc pertechnetate or I ${ }^{131} \quad$ A

Thyroid sonography is done in all patients with known thyroid nodule

Routine measurement of serum $\operatorname{Tg}$ (thyroglobulin) for initial evaluation of thyroid nodules is not recommended $\mathrm{F}$

The panel cannot recommend either for or against the routine measurement of serum calcitonin I

FNA is the procedure of choice in the evaluation of thyroid nodules

Ultrasound guided-FNA is recommended for nonpalpable, predominantly cystic, or posteriorly located thyroid nodule

Partially cystic nodules that repeatedly yield nondiagnostic aspirates need close observation or surgical excision. Surgery

should be strongly considered if the cytologically nondiagnostic nodule is solid

If a cytology result is diagnostic of or suspicious of papillary carcinoma thyroid, surgery is considered

Molecular markers (e.g., BRAF, RAS, RET/PTC, Pax8-PPARy, or galectin-3) may be considered for patients with

indeterminate cytology on FNA to help guide management

The panel cannot recommend for or against routine clinical use of ${ }^{18}$ FDG-PET scan to improve diagnostic accuracy of indeterminate thyroid nodules

If the cytology repots-

(i) follicular neoplasm and serum TSH is in the low-normal range, ${ }^{123}$ I may be considered. If an autonomously functionining nodule is not seen, lobectomy or total thyroidectomy should be considered

(ii) as suspicious for papillary/hurthle cell carcinoma, a radionuclide scan is not considered and either lobectomy or total thyroidectomy is recommended, depending on the size of the lesion, and other risk factors

(iii) as benign, further immediate diagnostic studies or treatment are not routinely required

In the presence of two or more thyroid nodules

(i) $>1 \mathrm{~cm}$ and those with the suspicious sonographic appearance, aspiration should be considered

(ii) if none of the nodules has a suspicious sonographic appearance and multiple sonographically similar coalescent nodules with no intervening normal parenchyma are present, it is reasonable to aspirate the largest nodules only and observe the others with serial ultrasound examinations

If serum TSH is low or low-normal technetium $99 \mathrm{mTc}$ pertechnetate or $123 \mathrm{I}$-scan should be done and it needs to be compared to the US images to determine functionality of each nodule $>1-1.5 \mathrm{~cm}$. FNA should then be considered only for those isofunctioning or nonfunctioning nodules, among which those with suspicious sonographic features should be aspirated preferentially

All benign thyroid nodules needs to be followed with serial ultrasound examinations for 6-18 months after the initial FNA-

(i) If nodule size is stable (i.e., no more than a $50 \%$ change in volume or $<20 \%$ increase in at least two nodule dimensions in solid nodules or in the solid portion of mixed cystic-solid nodules), the interval before the next follow-up clinical examination or ultrasound may be longer, e.g., every 3-5 years

(ii) If there is evidence for nodule growth either by palpation or sonographically (more than a $50 \%$ change in volume or a $20 \%$ increase in at least two nodule dimensions with a minimal increase of $2 \mathrm{~mm}$ in solid nodules or in the solid portion of mixed cystic-solid nodules), the FNA should be repeated, preferably with US guidance

Recurrent cystic thyroid nodules with benign cytology should be considered for surgical removal or per-cutaneous ethanol injection depending on pressure symptoms and cosmetic reasons

Routine suppression therapy of benign thyroid nodules in iodine sufficient populations is not recommended

Patients with growing benign nodules even after repeat biopsy should be considered for continued monitoring or intervention with surgery based on symptoms and clinical examination

\section{CHILDREN-}

The diagnostic and therapeutic approach to one or more thyroid nodules in a child should be the same as it would be in an adult

\section{PREGNANCY-}

(i) For euthyroid and hypothyroid pregnant women with thyroid nodules, FNA should be done. If TSH is suppressed, FNA may be deferred until after pregnancy and cessation of lactation, when a radionuclide scan can be performed to evaluate nodule function.

(ii) If cytology reports suggests PTC early in pregnancy, it should be monitored sonographically and if it grows substantially (as defined above) by 24 weeks gestation, surgery should be performed at that point. However, if it remains stable by midgestation or if it is diagnosed in the second half of pregnancy, surgery may be performed after delivery. In patients with more advanced disease, surgery in the second trimester is reasonable.

(iii) In pregnant women with FNA that is suspicious or diagnostic of PTC, administration of levothyroxine should be considered to keep the TSH in the range of $0.1-1 \mathrm{mU}=\mathrm{L}$ 
papillary tumors that are smaller than $1.5 \mathrm{~cm}$ in diameter grow slowly, and patients with such tumors have an excellent prognosis. It does not seem necessary, or costeffective to do a biopsy on or to surgically excise all nonpalpable nodulesor incidentalomas. The recommendedtreatment strategy is to observe incidentalomas that are smaller than $1.5 \mathrm{~cm}$ in diameter in patients who have a low risk for thyroid cancer. On the other hand, because nonpalpable papillary thyroid cancer is sometimes associated with local or even distant metastases, the incidentaloma cannot be dismissed as unimportant and careful follow-up is necessary. In patients who have nodules larger than $1.5 \mathrm{~cm}$ in diameter, a history of head or neck irradiation in childhood or in adulthood, a strong family history of thyroid cancer, or ultrasonographic findings that suggest malignancy, the next appropriate step is ultrasonographically guided biopsy. Treatment should then be determined on the basis of the cytologic diagnosis. Thyroxine suppressive therapy is not recommended for either a cytologically proven benign nodule that is larger than $1.5 \mathrm{~cm}$ in diameter or a benign-appearing nodule that is smaller than $1.5 \mathrm{~cm}$ in diameter detected ultrasonographically. Therefore, most nonpalpable nodules do not require immediate treatment and should be followed up simply with palpation. Biopsy should be done if and when the nodules become palpable. During follow-up, costly imaging with ultrasonography or radioisotope scanning is rarely indicated.

\section{References}

1. Brander A, Viikinkoski P, Tuuhea J, Voutilainen L, Kivisaari L (1992) Clinical versus ultrasound examination of the thyroid gland in common clinical practice. J Clin Ultrasound 20:37-42

2. Cook DM, Loriaux DL (1996) The incidental adrenal mass. Am J Med 101:88-94

3. Thyroid Incidentaloma. Hot Thyroidology. http//duncan.topliss@med. monash.edu.au

4. Boehm T, Rothouse L, Wartofsky L (1976) Metastatic occult follicular thyroid carcinoma. JAMA 235:2420-2421

5. Vander JB, Gaston EA, Dawber TR (1968) The significance of non-toxic thyroid nodules. Final report of a 15 -year study of the incidence of thyroid malignancy. Ann Int Med 69:537-540

6. Belfiore A, La Rosa GL, La Porta GA et al (1992) Cancer risk in patients with cold thyroid nodules; relevance of iodine intake, sex, age, and multinodularity. Am J Med 93:363-369

7. Rojeski MT, Gharib H (1985) Nodular thyroid disease. Evaluation and management. N Engl J Med 313:428-436

8. Sampson RJ, Woolner LB, Bahn RC, Kurland LT (1974) Occult thyroid carcinoma in Olmsted County, Minnesota: prevalence at autopsy compared with that in Hiroshima and Nagasaki, Japan. Cancer 34:2072-2076

9. Bondeson L, Ljungberg O (1981) Occult thyroid carcinoma at autopsy in Malmo, Sweden. Cancer 47:319-323

10. Fukunaga FH, Yatani R (1975) Geographic pathology of occult thyroid carcinomas. Cancer 36:1095-1099
11. Hanson GA, Komorowski RA, Cerletty JM, Wilson SD (1983) Thyroid gland morphology in young adults: normal subjects versus those with prior low-dose neck irradiation in childhood. Surgery 94:984-988

12. Wagner DH, Recant WM, Evans RH (1978) A review of one hundred and fifty thyroidectomies following prior irradiation to the head, neck and upper part of the chest. Surg Gynecol Obstet 147:903-908

13. Mazzaferri EL (1993) Management of a solitary thyroid nodule. N Engl J Med 328:553-559

14. Kasper DL, Braunwald E, Fauci AS (2005) Harrison's principles of internal medicine. McGraw-Hill, New York, pp 2104-2127

15. Siminoski K (1995) Does this patient have a goiter? JAMA 273:813-817

16. Tan GH, Gharib H, Reading CC (1995) Solitary thyroid nodule. Comparison between palpation and ultrasonography. Arch Intern Med 155:2418-2423

17. Christensen SB, Tibblin S (1985) The reliability of the clinical examination of the thyroid gland. A prospective study of 100 consecutive patients surgically treated for hyperparathyroidism. Ann Chir Gynaecol 74:151-154

18. McHenry C, Smith M, Lawrence AM, Jarosz H, Paloyan E (1988) Nodular thyroid disease in children and adolescents: a high incidence of carcinoma. Am Surg 54:444-447

19. Psarras A, Papadopoulos SN, Livadas D, Pharmakiotis AD, Koutras DA (1972) The single thyroid nodule. Br J Surg 59:545-548

20. Belfiore A, La Rosa GL, Padova G, Sava L, Ippolito O, Vigneri R (1987) The frequency of cold thyroid nodules and thyroid malignancies in patients from an iodine-deficient area. Cancer 60:3096-3102

21. Hamming JF, Goslings BM, van Steenis GJ, van Ravenswaay CH, Hermans J, van de Velde CJH (1990) The value of fine-needle aspiration biopsy in patients with nodular thyroid disease divided into groups of suspicion of malignant neoplasms on clinical grounds. Arch Intern Med 150:113-116

22. Mortensen JD, Woolner LB, Bennett WA (1955) Gross and microscopic findings in clinically normal thyroid glands. J Clin Endocrinol Metab 15:1270-1280

23. Komorowski RA, Hanson GA (1988) Occult thyroid pathology in the young adult: an autopsy study of 138 patients without clinical thyroid disease. Hum Pathol 19:689-696

24. Horlocker TT, Hay JE, James EM, Reading CC, Charboneau JW (1985) Prevalence of incidental nodular thyroid disease detected during high-resolution parathyroid ultrasonography. In: Medeiros-Neto G, Gaitan E (eds) Frontiers in thyroidology. Plenum Medical, New York, pp 1309-1312

25. Brander A, Viikinkoski P, Nickels J, Kivisaari L (1991) Thyroid gland: US screening in a random adult population. Radiology 181:683-687

26. Pacini F, Vorontsova T, Demidchik E, Molinaro E, Agate L, Romei C, Shavrova E, Cherstvoy ED, Ivashkevitch Y, Kuchinskaya E, Schlumberger M, Ronga G, Filesi M, Pinchera A (1997) Post-Chernobyl thyroid carcinoma in Belarus children and adolescents: comparison with naturally occurring thyroid carcinoma in Italy and France. J Clin Endocrinol Metab 81:3563-3569

27. Boelaert K, Horacek J, Holder RL, Watkinson JC, Sheppard MC, Franklyn JA (2006) Serum thyrotropin concentration as a novel predictor of malignancy in thyroid nodules investigated by fineneedle aspiration. J Clin End Metab 91:4295-4301

28. Pacini F, Pinchera A, Giani C, Grasso L, Baschieri L (1980) Serum thyroglobulin in thyroid carcinoma and other thyroid disorders. Clin Endocrinol 13:107-110

29. Costante G, Meringolo D, Durante C, Bianchi D, Nocera M, Tumino S, Crocetti U, Attard M, Maranghi M, Torlontano M, 
Filetti S (2007) Predictive value of serum calcitonin levels for preoperative diagnosis of medullary thyroid carcinoma in a cohort of 5817 consecutive patients with thyroid nodules. J Clin Endocrinol Metab 92:450-455

30. Cheung K, Roman SA, Wang TS, Walker HD, Sosa JA (2008) Calcitonin measurement in the evaluation of thyroid nodules in the United States: a cost-effectiveness and decision analysis. J Clin Endocrinol Metab 93:2173-2180

31. Gagel RF, Hoff AO, Cote GJ (2005) Medullary thyroid carcinoma. In Werner and Ingbar's The Thyroid. Lippincott Williams and Wilkins, Philadelphia, pp 967-988

32. Danese D, Sciacchitano S, Farsetti A, Andreoli M, Pontecorvi A (1998) Diagnostic accuracy of conventional versus sonographyguided fine-needle aspiration biopsy of thyroid nodules. Thyroid 8:15-21

33. Alexander EK, Heering JP, Benson CB, Frates MC, Doubilet PM, Cibas ES, Marqusee E (2002) Assessment of nondiagnostic ultrasound-guided fine needle aspiration of thyroid nodules. J Clin Endocrinol Metab 87:4924-4927

34. Baloch ZW, LiVolsi VA, Asa SL, Rosai J, Merino MJ, Randolph G, Vielh P, DeMay RM, Sidawy MK, Frable WJ (2008) Diagnostic terminology and morphologic criteria for cytologic diagnosis of thyroid lesions: a synopsis of the National Cancer Institute Thyroid Fine-Needle Aspiration State of the Science Conference. Diagn Cytopathol 36:425-437

35. Noguchi S, Yamashita H, Uchino S, Watanabe S (2008) Papillary microcarcinoma. World J Surg 32:747-753

36. Wada N, Duh QY, Sugino K, Iwasaki H, Kameyama K, Mimura T, Ito K, Takami H, Takanashi Y (2003) Lymph node metastasis from 259 papillary thyroid microcarcinomas: frequency, pattern of occurrence and recurrence, and optimal strategy for neck dissection. Ann Surg 237:399-407

37. Hemminki K, Eng C, Chen B (2005) Familial risks for nonmedullary thyroid cancer. J Clin Endocrinol Metab 90:5747-5753

38. Schneider AB, Ron E, Lubin J, Stovall M, Gierlowski TC (1993) Dose-response relationships for radiation-induced thyroid cancer and thyroid nodules: evidence for the prolonged effects of radiation on the thyroid. J Clin Endocrinol Metab 77:362-369

39. Shibata Y, Yamashita S, Masyakin VB, Panasyuk GD, Nagataki S (2001) 15 years after Chernobyl: new evidence of thyroid cancer. Lancet 358:1965-1966

40. Leenhardt L, Hejblum G, Franc B, Fediaevsky LD, Delbot T, Le Guillouzic D, Me'ne'gaux F, Guillausseau C, Hoang C, Turpin G, Aurengo A (1999) Indications and limits of ultrasound-guided cytology in the management of nonpalpable thyroid nodules. J Clin Endocrinol Metab 84:24-28

41. Jeh SK, Jung SL, Kim BS, Lee YS (2007) Evaluating the degree of conformity of papillary carcinoma and follicular carcinoma to the reported ultrasonographic findings of malignant thyroid tumor. Korean J Radiol 8:192-197

42. Machens A, Holzhausen HJ, Dralle H (2005) The prognostic value of primary tumor size in papillary and follicular thyroid carcinoma. Cancer 103:2269-2273

43. Frates MC, Benson CB, Doubilet PM, Kunreuther E, Contreras M, Cibas ES, Orcutt J, Moore FD Jr, Larsen PR, Marqusee E, Alexander EK (2006) Prevalence and distribution of carcinoma in patients with solitary and multiple thyroid nodules on sonography. J Clin Endocrinol Metab 91:3411-3417

44. Bonavita JA, Mayo J, Babb J, Bennett G, Oweity T, Macari M, Yee J (2009) Pattern recognition of benign nodules at ultrasound of the thyroid: which nodules can be left alone? AJR Am J Roentgenol 193:207-213

45. Rago T, Santini F, Scutari M, Pinchera A, Vitti P (2007) Elastography: new developments in ultrasound for predicting malignancy in thyroid nodules. J Clin Endocrinol Metab 92:29172922
46. Cooper DS, Doherty GM, Haugen BR, Kloos RT, Lee SL, Mandel SJ, Mazzaferri EL, McIver B, Sherman SI, Tuttle RM (2009) The American Thyroid Association Guidelines Taskforce. Management guidelines for patients with thyroid nodules and differentiated thyroid cancer. Thyroid 16:1167-1176

47. Delbeke D (1999) Oncological applications of FDG PET imaging: brain tumors, colorectal cancer, lymphoma and melanoma. J Nucl Med 40:591-603

48. Chen YK, Ding HJ, Chen KT et al (2005) Prevalence and risk of cancer of focal thyroid incidentaloma identified by $18 \mathrm{~F}$ fluorodeoxyglucose positron emission tomography for cancer screening in healthy subjects. Anticancer Res 25:1421-1426

49. Cohen MS, Arslan N, Dehdashti F et al (2001) Risk of malignancy in thyroid incidentalomas identified by fluorodeoxyglucose - positron emission tomography. Surgery 130:941-946

50. Kim TY, Kim WB, Ryu JS, Gong G, Hong SJ, Shong YK (2005) 18 F-fluorodeoxyglucose uptake in thyroid from positron emission tomogram (PET) for evaluation in cancer patients: high prevalence of malignancy in thyroid PET incidentaloma. Laryngoscope 115:1074-1078

51. Mitchell JC, Grant F, Evenson AR, Parker JA, Hasselgren PO, Parangi S (2005) Preoperative evaluation of thyroid nodules with 18FDG-PET/CT. Surgery 138:1166-1174, discussion 1174-1175

52. Gordon BA, Flanagan FL, Dehdashti F (1997) Wholebody positron emission tomography: normal variations, pitfalls, and technical considerations. AJR 169:1675-1680

53. Rallison ML, Dobyns BM, Keating FR Jr, Rall JE, Tyler FH (1975) Thyroid nodularity in children. JAMA 233:1069-1072

54. Corrias A, Einaudi S, Chiorboli E, Weber G, Crino A, Andreo M, Cesaretti G, de Sanctis L, Messina MF, Segni M, Cicchetti M, Vigone M, Pasquino AM, Spera S, de Luca F, Mussa GC, Bona G (2001) Accuracy of fine needle aspiration biopsy of thyroid nodules in detecting malignancy in childhood: comparison with conventional clinical, laboratory, and imaging approaches. J Clin Endocrinol Metab 86:4644-4648

55. Tan GH, Gharib H, Goellner JR, van Heerden JA, Bahn RS (1996) Management of thyroid nodules in pregnancy. Arch Intern Med 156:2317-2320

56. Moosa M, Mazzaferri EL (1997) Outcome of differentiated thyroid cancer diagnosed in pregnant women. J Clin Endocrinol Metab 82:2862-2866

57. Mestman JH, Goodwin TM, Montoro MM (1995) Thyroid disorders of pregnancy. Endocrinol Metab Clin North Am 24:41-71

58. Kuy S, Roman SA, Desai R, Sosa JA (2009) Outcomes following thyroid and parathyroid surgery in pregnant women. Arch Surg 144:399-406

59. Rosen IB, Korman M, Walfish PG (1997) Thyroid nodular disease in pregnancy: current diagnosis and management. Clin Obstet Gynecol 40:81-89

60. Singer PA, Cooper DS, Daniels GH, Ladenson PW, Greenspan FS, Levy EG, Braverman LE, Clark OH, McDougall IR, Ain KV, Dorfman SG (1996) Treatment guidelines for patients with thyroid nodules and well-differentiated thyroid cancer. American Thyroid Association. Arch Intern Med 156:2165-2172

61. Kuma K, Matsuzuka F, Yokozawa T, Miyauchi A, Sugawara M (1994) Fate of untreated benign thyroid nodules: results of longterm follow-up. World J Surg 18:495-498

62. Carmeci C, Jeffrey RB, McDougall IR, Nowels KW, Weigel RJ (1998) Ultrasound-guided fine-needle aspiration biopsy of thyroid masses. Thyroid 8:283-289

63. McCoy KL, Jabbour N, Ogilvie JB, Ohori NP, Carty SE, Yim JH (2007) The incidence of cancer and rate of false-negative cytology in thyroid nodules greater than or equal to $4 \mathrm{~cm}$ in size. Surgery 142:837-844

64. Alexander EK, Hurwitz S, Heering JP, Benson CB, Frates MC, Doubilet PM, Cibas ES, Larsen PR, Marqusee E (2003) Natural 
history of benign solid and cystic thyroid nodules. Ann Int Med 138:315-318

65. Asanuma K, Kobayashi S, Shingu K, Hama Y, Yokoyama S, Fujimori M, Amano J (2001) The rate of tumour growth does not distinguish between malignant and benign thyroid nodules. Eur J Surg 167:102-105
66. Brauer VF, Eder P, Miehle K, Wiesner TD, Hasenclever H, Paschke R (2005) Interobserver variation for ultrasound determination of thyroid nodule volumes. Thyroid 15:1169-1175

67. Oertel YC, Miyahara-Felipe L, Mendoza MG, Yu K (2007) Value of repeated fine needle aspirations of the thyroid: an analysis of over ten thousand FNAs. Thyroid 17:1061-1066 